crackers and milk, which furnished 0.0057 gram iron and 2.65 grams calcium oxide (Exp. I), there was equilibrium with respect to iron, and a storage of calcium. When the diet consisted of crackers and egg-white with 0.0065 gram iron and 0.14 gram lime (Exp. II), or of crackers alone with $0.007 \mathrm{I}$ gram iron and 0.13 gram lime (Exp. III), there were losses of both iron and calcium. These losses occurred through the intestine, but were evidently not due to intestinal putrefaction, since the ratio of sulphur in ethereal to that in simple sulphates in the urine was determined in Exp. III and found to be as $I: 25$. The results appear to confirm the suggestion of Von Wendt that a deficiency of calcium in the diet may lead to a loss of iron as well as of calcium from the body. There was a slight tendency toward diarrhea in each of the periods in which loss of iron and calcium occurred. The iron requirement evidently varied greatly, the average daily output for three experiments being 5.5, 8.7 and I 2.6 milligrams respectively.

The lime requirement was found by further experiments (IV and V) to be about 0.75 gram of calcium oxide per day.

The experiments were conducted at Columbia University in cooperation with the U. S. Department of Agriculture and will be described in detail in a bulletin of the Office of Experiment Stations of that department.

19 (162)

\title{
The cause of the treppe.
}

\section{By FREDERIC S. LEE.}

[From the Physiological Laboratory of Columbia University, at the College of Physicians and Surgeons.]

The treppe is usually ascribed to increased irritability caused by activity. The cause of the increased irritability has remained obscure. In studying the depressing action on muscle of its fatigue substances the author often observed augmentation of activity instead of depression. A more careful investigation of this phenomenon shows that it may be produced by all of the three recognized fatigue substances - namely, carbon dioxide, monopotassium phosphate, and paralactic acid. When a muscle is irrigated with an indifferent fluid containing one of these substances in 
small quantity, and compared with its mate irrigated only by the indifferent fluid, a fatigue record being made from both, more intense contractions frequently occur in the poisoned muscle at the beginning of the experiment, and may last until exhaustion sets in. When a fatigue record is being made from a muscle with the circulation intact, intravenous injection of a fatigue substance causes augmentation of contraction. The author concludes that the treppe is due to the augmenting action of fatigue substances in small quantities - the same substances which in larger quantities cause depression or fatigue.

An excellent mode of demonstrating the augmenting action of $\mathrm{CO}_{2}$ in the cat is to record the contractions of the tibialis anticus in the living animal, and while the record is being made, to clamp the trachea. A marked treppe follows.

If two corresponding muscles be compared, one with the circulation intact, and the other with its arteries ligated, the latter muscle performs more intense contractions and exhibits a more rapidly developing treppe, owing to the accumulation of fatigue substances.

The chemical theory of the treppe is able to explain several other known phenomena. The author has experimented on both frogs and cats. The augmenting action of the fatigue substances seems to be observed even when curare is employed.

$$
20 \text { (I63) }
$$

The influence of the red corpuscles upon the viscosity of the blood.

\section{BY RUSSELL BURTON-OPITZ.}

[From the Physiological Laboratory of Columbia University, at the College of Physicians and Surgeons.]

The method by means of which the following determinations of the viscosity were made has been described in Pflüger's Archiv, Vol. 82, p. 464.

Having determined the coefficient for fresh ox serum at $37^{\circ} \mathrm{C}$. the serum was gradually concentrated by the addition of definite quantities of red blood corpuscles (washed). The viscosity of the "blood" was tested after each addition of corpuscles. 